Article

\title{
Impact of UEFA Champions League and UEFA Europa League on Financial Sustainability-Case Study of Two Small Football Portuguese Teams
}

\author{
Florbela Dantas ${ }^{1}$, Ana Borges ${ }^{1}$ (D) and Rui Silva ${ }^{2, *(1)}$ \\ 1 CIICESI, Escola Superior de Tecnologia e Gestão, Politécnico do Porto, 4200-465 Porto, Portugal; \\ 8150009@estg.ipp.pt (F.D.); aib@estg.ipp.pt (A.B.) \\ 2 CETRAD, University of Trás-os-Montes e Alto Douro, 5000-801 Vila Real, Portugal \\ * Correspondence: ruisilva@utad.pt
}

Received: 27 September 2020; Accepted: 2 November 2020; Published: 5 November 2020

\begin{abstract}
Qualifying for European competitions allows football clubs to have access to the two most important football competitions played in Europe, UEFA Champions League and UEFA Europa League. Thereby, participation in these important competitions has both direct (participation prizes) and indirect (player transactions, television rights, box office, advertising, sponsorship) impacts on the sustainability of European football clubs' accounts. The current competition model, which now includes more football teams, has become more attractive for small clubs. In this context, this research aims to analyze the impact of qualification for European competitions on the sustainability of a strong economic and financial structure of small clubs through a case study analysis of two small Portuguese clubs. The quantitative analysis is also supported by a comparative analysis, which was reinforced with nonparametric statistical analysis. The results show that the economic and financial impact on small clubs was not immediate, but was beneficial if it was managed efficiently. This research contributes to increasing knowledge of the decision-making agents of clubs that are participating for the first time in European competitions, or, if recurrent, are seeking answers and guidelines for the effective management of football teams.
\end{abstract}

Keywords: football; UEFA Champions League; UEFA Europa League; financial sustainability; small football teams; management

\section{Introduction}

The growth and importance of European competitions in the "king sport" panorama has attracted the attention and interest of the scientific community. Several studies have been carried out, both in terms of financial and sports impact as well as in terms of being a social phenomenon [1]. The competitions that attract the most interest for clubs are the UEFA Champions League (UCL) and the UEFA Europa League (UEL) [1]. For the past 20 years, UEFA has worked on improving the format of European competitions to ensure they are a highly profitable business [1]. The UEFA Champions League (hereinafter referred to as UCL) and the UEFA Europa League (hereinafter referred to as UCL) are the main and most sought-after competitions for European clubs, not only for the financial aspect (direct revenue from participation prizes) but also for indirect benefits (new fans and international sponsors) [2]. Participation in UCL and UEL is determined by the UEFA Club Ranking (available at https://www.footballseeding.com/club-ranking/a2018-2019/ (accessed in 23 May 2019)) which, as a result of successive changes to the format of competitions, now allows it to cover more European clubs, making football more financially balanced in terms of the distribution of monetary prizes, and more competitive in terms of sports [3]. 
Historically, there has been a certain polarization of participating clubs; generally, the elite of European football dominate not only national competitions but also those in Europe [2]. Europe's elite football clubs consist of 30 clubs, according to the ranking defined by the consultancy Deloitte's Football Money League, which is based on the revenues generated by clubs. Additionally, they possess high growth rates and a brand name with a global reach [2]. Currently, we have seen that other clubs, mainly those that are smaller, also reach this desired qualification [1]. The most recent and mediatic participation belonged to Leicester City FC in the 2015/2016 season, a club in the competitive Premier League. At the national level in Portugal, this highlight goes to Vitória SC and FC Paços de Ferreira. This new reality opens the way for further research, but using a new approach to the objects of study.

The existing literature on this topic relating European competitions with the financial aspects of clubs focuses essentially on the regulations created by UEFA (Financial Fair Play (FFP)) and neglects the financial impacts of participating in competitions. The introduction of FFP as a measure to combat indebtedness and restoration of the financial sustainability of European clubs in a crisis (partly caused by the excessive investment of clubs in players to reach a better place in European competitions) ended up creating an apparent link between European competitions and application of the regulation. What is verified in the literature is an orientation of the studies that relate to participation in European competitions and FFP. However, despite this, it is possible to discover some studies that analyze these impacts, but these only involve clubs with regular participation in these competitions, generally large clubs or leagues [4], and seek to relate qualification to changes in the various dimensions. For example, there seems to be a relation between the qualification and the debt of European clubs. An investigation carried out within the French league context revealed that the demand for superstars that imply sporting success, both nationally and through qualification, seems to condemn the clubs to indebtedness in the case where the club does not recover the investment with qualification [5]. This study is in line with more research that showed that the excessive demand for the best player to build the best team and achieve the longed-for participation in UCL has, in the past, led many European clubs to excessive indebtedness [6].

It is also possible to find a relation between qualification to UEL and the impact on the national league. There is evidence of benefits for clubs participating in European competitions; however, when compared to the wealth generated by UCL and the Premier League, for example, the benefit is highly sensitive to the costs associated with players [7]. Still, regarding the wealth generated, there seems to be an inequality in the amounts of prizes awarded to clubs in the UCL [8]. Despite these studies, and at the time of this analysis, there is no known literature focusing on small clubs and the relationship between qualification and its financial sustainability. Moreover, there is the issue of FFP; although the regulation applies to all clubs participating in European competitions, investigations have not yet addressed its effects on the financial sustainability of these types of teams in particular. Taking into account the various existing studies relating to European competitions and economic and financial difficulties, the authors seek to empirically examine the relationship between qualification, economic and financial performance, financial sustainability, and the existence of a causal impact, answering the following questions: Does qualification for European competition affect the qualitative development and quantitative economic and financial growth of small clubs? Are the economic and financial sustainability impacts immediate? Which revenue sources are most affected? Are clubs and their decision-makers prepared at this level, with organizational structures for these purposes? The answers to these questions will allow for the early identification of events, positive or negative, that may arise during the three phases of qualification (qualification, participation, and post participation). The results aim to serve as guidance and to raise awareness of these small clubs and their limitations in terms of organizational structures and, thus, adopt more rational attitudes, avoiding negative consequences in both the short and long term.

This article contributes to theoretical and practical knowledge in several ways. First, it contradicts the dominant paradigm concerning the objects of study in this area, which are generally big clubs. For these clubs, interestingly, the direct impact (participation fees and ticket revenues) is not significant 
(between 10 and $25 \%$ of their budget), while the indirect impact (commercial activities, marketing, transfers) is higher [1]. The same is not necessarily true for clubs with lower incomes, since the direct impact (between 40 and $60 \%$ of the budget) is decisive for certain clubs to develop their activities [1], which makes a deeper investigation relevant to the reality of these clubs. Secondly, it deepens one of the main dimensions of the performance of football clubs, the financial part, and the relationship between the sustainability of that dimension and the participation in European competitions. Finally, it contributes to increasing the knowledge of the decision-making agents of the clubs which are facing participation in European competitions for the first time, or those who, being recurrent, seek answers and guidelines for the management of the process. This study was carried out in the context of the first Portuguese football division (Liga Portugal) and provides clear indications of the economic and financial impacts at different times of the competitions.

The data reveal that participation in European competitions affected the qualitative development of the analyzed sample; the same is not true, however, regarding quantitative economic-financial growth, which calls into question the relationship between qualification and the participants' financial sustainability. It was also possible to assess that the impacts at the economic and financial level are not immediate, and that the players' transactions are the source of revenue where the impact is most significant. Finally, the sample allowed us to verify that, in a broad sense, qualification for European competitions can be beneficial if the process is managed efficiently.

\section{Literature Review}

\subsection{Financial Sustainability}

Financial sustainability is a description of the steady excess of enterprise revenues and the continuous process of free maneuvering and utilizing the enterprise's money-a continuous process of production and sales. Financial stability is formed during production and economic activities and is a key component of the overall sustainability of the enterprise [9]. The financial sustainability of companies, in general, can be assessed using several indicators [9]. At the level of the football industry, in particular, the transformation of football clubs into companies brought the reality of the clubs and the need for financial sustainability closer to that of the business world. The soccer business is currently seen as a business activity that is also seeking sustainability [10]. In European management literature, there is no standardization as to the expression to be applied to classify the indicators used in the financial analysis process (financial indicators, economic indicators, economic-financial indicators). Bearing in mind that in this analysis, there is a crossover of balance sheet and income statement items, the indicators are referred to as economic and financial indicators.

\subsection{Financial Sustainability of European Football Clubs}

The high interest of clubs in qualifying for the most important competitions in Europe is understandable considering the value of the prizes [1]. However, the overwhelming demand for the best player to build the best team and achieve participation in UCL has led many European clubs into excessive debt [6]. This context of financial crisis, into which some of the main European teams have plunged, has led to reflection by UEFA. To restore the financial sustainability of teams, UEFA approved, in 2009, a set of measures that became known as Financial Fair Play (FFP), which took effect in the 2011/2012 season. In the previous literature, it is already possible to find studies that assess the financial sustainability of clubs after the introduction of FFP. Authors such as Barajas, Castro-Limeres and Gasparetto [11] have seen progressive improvements in the stability and financial sustainability of the main European football clubs and have shown that UEFA's financial control has great benefits. A previous study associated the introduction of FFP with changes in the financial results of European football clubs; however, these changes did not produce a significant improvement in overall financial sustainability [12]. Despite the various studies which focus on financial sustainability and its relationship with the introduction of FFP, one of the drivers of the regulation, European competitions, 
is not being properly analyzed in the literature. For this reason, we have defined the following research hypothesis:

Hypothesis 1. The financial sustainability of small clubs is associated with qualifications in European competitions.

In a study carried out on the business model of European competitions [1], the author states that the direct impact of qualification in European competitions of teams with incomes below 100 million euros is greater ( 40 to $60 \%$ of the budget), and in majority of cases, the club must develop its activity. In this sense, the new format of European Club competitions, which now include more teams to attract more fans, sponsors, and partnerships with the media [1], has become more financially attractive to clubs, which have started to invest more in their teams to reach a place in competitions; in some cases, however, over-budget investment has led to excessive indebtedness. The study, "The European Dilemma: Evaluating the Implications of UEFA Europa League Participation on English Premier League Clubs" by [7], on the implications of the UEFA Europa League in the Premier League reports the tensions suffered by the financially precarious clubs, who see qualifying for UEL as an opportunity. This stance resulted in European clubs spending large amounts on transfers and player salaries, placing them in a scenario of financial instability [13]. Studies point out that the attempt to overcome successful, structured clubs, organized at all levels, by small clubs, leads to indebtedness. However, it is not very clear whether this indebtedness is directly influenced by the search for qualification or, on the contrary, it results from a set of situations. Because of this, we present the hypothesis below:

Hypothesis 2. Qualification for European competitions influences the sustainability of small clubs.

For many clubs, sporting success means obtaining returns, so clubs mobilize their resources and adopt a posture of greater investment. However, and according to Andreff [5], this attitude condemns the clubs to indebtedness if the objective is not met, and the clubs do not recover the investment. Sport, in particular, professional football, has in recent decades become one of the sectors of activity with the greatest potential to generate revenues. This transformation forced the professionalization of the clubs and their staff. These changes took place not only in terms of their organizational structures, which are now more appropriate, but also in terms of management bodies [14]. The professionalization of the clubs highlighted the importance of business management in the football industry. This is currently observed in a parallel between the businesses of traditional companies and the activities of football clubs, with the latter gaining such importance that in some cases it surpasses traditional companies [15]. In small clubs, professionalization took place mainly with the introduction of FFP, which includes, among others, a set of rules that must be followed by the clubs that intend to participate in European competitions. Management teams are responsible for making decisions that support the entire process of participating in competitions. Based on this idea and a literature review, we formulated the research hypothesis below:

Hypothesis 3. The sustainable management of the participation process in European competitions influences the economic and financial balance of small clubs.

The management of a club by professionals with management knowledge can change the direction of a financially unbalanced club. A study conducted at FC Barcelona [15] identified a clear relationship between management strategies and the positive evolution of financial performance. The measures taken by the management bodies were decisive for the club to become one of the best in the world.

\section{Problem Formulation}

To answer the formulated questions, the financial dimension will be used as a background, which contains fundamental variables for understanding the economic and financial performance. Based on the variables in the financial statements, indicators were constructed and calculated which, 
according to the literature, allow for the assessment of a club's economic and financial performance. The answers to the two central questions about qualitative development and quantitative economic and financial growth form two pillars that support and answer another question: Who is responsible for the team's financial sustainability? According to the literature, the assessment of corporate financial sustainability, in general, involves the analysis of economic and financial indicators [9].

The approach given is to find answers to questions essential to the viability of a club: What is the equity situation? What financial resources are available to meet operational needs? How intensely is external capital used? What is the capacity to generate profits? What is the availability of equity capital concerning equity capital? What factors contribute to the formation of income and expenses? Which management policies ensure the club's permanence in the market and, at the same time, its expansion?

\subsection{Sample}

For the present analysis, two Portuguese sports societies in the Portuguese Premier League (Liga Portugal) (https://www.ligaportugal.pt/pt/homepage/ (accessed on 23 May 2019)) that qualified for European competitions (hereinafter referred to as SAD A and SAD B) were chosen from a population of 13. SAD A participated in the UCL, SAD B participated in the UEL. Regarding the criteria used for the selection of the sample, taking into account that the participants requested anonymity and, thus, to avoid their identification, the authors can only clarify that the basis was the number of qualifications for European competitions and the geographical location of the clubs. The choice of the time frame to be analyzed, 2008-2018, was based on the comparability of sporting circumstances. The data necessary for the investigation were made available by the clubs.

\subsection{Methodology}

This article seeks to measure the impact, qualitative and quantitative, of participation in European competitions by small clubs. The assessment can be carried out from different dimensions (sporting, financial, commercial) [2]. However, taking into account that football is a business and that for these clubs, the financial dimension is the guarantee of its continuity [1], the dimension to be analyzed is the economic-financial one. Using the available data, the intention was to identify the timing of these impacts, the revenue sources most affected, and the implications for decision making. This is a study that involves an exploratory analysis of the time series of the indicators since it allows observing the economic and financial trajectory of the sample and the variations in the variables of interest in the three phases of qualification (qualification, participation, and post participation).

The information obtained relates to the account reports and the financial statements of the sports seasons between 2008 and 2018. The period chosen was motivated by being the one that preceded and proceeded to the qualification of both clubs. In total, 20 financial statements and respective management reports were analyzed. The data of the desired information were organized according to sports seasons using Excel maps. These maps were previously parameterized, using mathematical formulas, to also obtain the economic and financial indicators and respective values. The next step was the calculation of ratios and indicators and their interpretation.

To obtain better consistency of results, the comparative analysis was reinforced with statistical analysis of the temporal evolution of the main indicators, where a structural change of the time series was sought. This structural change, i.e., point of change, would be related to the effect of qualification on the values of indicators. To understand if the qualification for European competitions imposes a statistically significant effect on the progression of each indicator, the Wilcoxon rank test [9] was performed at a $5 \%$ significant level. Here, the null hypothesis being tested is that the distributions of the indicator values before qualification and the indicator values after qualification differ by a zero-location shift of the median (i.e., the distribution has identical median location). The choice of this method was inspired by the work of [10], where they proposed detecting structural changes in time series using local Wilcoxon statistics. These authors highlight that in the one-dimensional case, the Wilcoxon rank 
test procedure correctly detects differences in the location of a rich class of populations. As our dataset is small in size, an assumption regarding data distribution would be a risk and, thus, a non-parametric methodology seems adequate.

Additionally, the structural breakdown detection methodology, that is, significant change points in the average progression of a variable over time, is applied in several areas and, in particular, in the areas of finance [16-18].

\subsection{Variables}

All variables were parameterized using the tangible assets (TA) and intangible assets (IA) that provided us with information on the assets and investments made by the studied clubs, which allows for an analysis of the effects of qualification on their qualitative development. We also calculated economic and financial indicators, which are described in the following paragraph, that result from the analysis of accounting headings, allowing us to identify the significant changes that have occurred, and which variables have caused these changes.

Tangible and intangible assets provide information about the club's assets and investments, which allows for analysis of the effects of qualification on the qualitative development of the club. All calculated indicators result from the ratio of accounting items, allowing identification in accounting terms, where there have been significant changes, and of which variables have caused these changes. The general liquidity indicator, which results from the ratio between current assets and current liabilities, makes it possible to assess whether the financial means available results from the existing returns with qualification. In accounting literature, current assets reflect the assets and rights of any company that is expected to be realized, sold, or consumed in the normal course of the company's operating cycle, and is held essentially to be traded and to be realized in twelve months after the balance sheet date. Current liabilities are related to the obligations of a company that become liquidated within one year. The value that results from the ratio between current assets and current liabilities, in the case of the football clubs under analysis, gives us the financial means available. In Table 3, the combination of this result with the variables allows us to verify whether these available financial means result, or not, from the existing returns with qualification. The indebtedness indicator, obtained through the ratio of liabilities to assets when providing data on the intensity of recourse to foreign capital to finance the activity, allows for assessment of the management capacity of the available financial resources. As it is an indicator that is related to financing and investments, and taking into account that in small football clubs, it is up to the management bodies to make strategic decisions in these matters, the need for an intense search for other people's resources may indicate the absence, on the part of the managers, of a careful analysis of the risks associated with this exposure. The excessive demand for these capitals can be a sign of poorly sustained decision-making or a sign of insufficient available financial resources. In this sense, either of these two issues is related to managers and decision making and, therefore, the indebtedness indicator gives us these data. The solvency indicator, obtained through the ratio between equity and liabilities, allows not only assessing the ability to generate profits but also the availability of equity to cover the obtained credits. In this sense, as the numerator of the solvency indicator, equity, incorporates, among other items, the net result for the period (profit generated). Based on the solvency ratio, it is thus possible to verify whether equity, including profit generated, is positive, expressive, and sufficient to cover credits. From a more commercial perspective, some income items will be analyzed to understand the most affected revenue sources.

In addition, the variables in the income account heading provide data on the impact of qualification on the five main sources of revenue for football clubs: athletes' rights (earnings from transaction and assignment), television rights (selling rights to games at home), competitions (participation in national and European events), commercial activity (sponsorship, advertising, and corporate), and ticket revenues. 
According to the abovementioned, the main objective of this study is to verify if the participation of small clubs in the European competitions UCL and UEL is associated with greater financial sustainability, and which variables best express this association.

\section{Results}

Regarding the question of qualification and whether it affects qualitative development, we carried out an analysis of the TA and IA variables in the last five sporting seasons (which coincided with the teams' qualification to European competitions) comparing the investments made by the clubs. Table 1 focuses only on investments made in infrastructures (TA) and in the squad (players) (IA) and they are gross amounts, without amortization, and related to each season (i.e., they are not accumulated amounts). Based on the results of the last five sporting seasons (Table 1), it is evident that the investment made into assets in the year of qualification and in the following seasons suggests that qualification affects qualitative development. A more detailed analysis reveals that these investments were made in different sectors: on the one hand, SAD A opts for investment in tangible assets (infrastructure); on the other, SAD B opts for the valuation of its intangible assets (squad).

Table 1. Investments made in tangible assets (TA) (infrastructure) and intangible assets (IA) (squad) over the last five sports seasons.

\begin{tabular}{ccccccc}
\hline & $\mathbf{2 0 1 3 / 1 4} *$ & $\mathbf{2 0 1 4 / 1 5 *}$ & $\mathbf{2 0 1 5 / 1 6 *}$ & $\mathbf{2 0 1 6 / 1 7} *$ & $\mathbf{2 0 1 7 / 1 8} *$ & $\begin{array}{c}\text { Total } \\
\text { Investments * }\end{array}$ \\
\hline SAD A & Qualification & - & - & - & - & - \\
TA & $1,232,725$ & 614,544 & 738,451 & $1,956,269$ & 855,780 & $5,397,769$ \\
IA & $2,430,000$ & 90,287 & 229,000 & 350,000 & 200,000 & $3,299,287$ \\
SAD B & & & & & \\
TA & 43,250 & 237,666 & 196,457 & 149,346 & 518,701 & $1,145,420$ \\
IA & 661,050 & 178,500 & 700,000 & $7,214,375$ & 806,197 & $9,560,122$ \\
\hline
\end{tabular}

* All Values in Euros.

According to the accounting literature, an asset is a resource controlled by an entity as a result of past events and from which future economic benefits are expected to flow. A tangible asset is an asset held for use in the production or supply of goods or services and which is expected to be used for more than one period. The intangible asset, in turn, is a non-monetary asset, identifiable without physical substance. In Table 2, we can see all investments made in the period under review, 2008-2009 to 2017-2018, in TA and IA, with values that are net (i.e., that include amortizations and are accumulated values). In this table, the values related to investments include other types of investments; as an example, we have investments in transport equipment. Moreover, to further analyze the variables TA and IA, accounting items (partners and financing obtained from $c / p$ ) are presented, which indicate the main sources of investment financing. It is also possible to find different ways of financing these investments: in the case of SAD A, the use of a single partner (Table 2), to detriment of exposure to banking, was the strategy that was followed; in the case of SAD B, it was the income from the transaction of players (Table 2) who contributed most to investments. Although there are signs of qualitative development, we believe that the main driver of investment is beyond the financial returns of qualification, especially if the investments are made with intensity before the direct financial inflows. In the case of SAD A, the investments were made using equity. Thus, we understand that there may be two drivers: (1) short-term, the feeling of belonging to the elite; (2) long-term, expected to increase business. There is a qualitative improvement in the sample as a result of qualification; however, the revenues from participation bonuses (direct impacts) do not seem to directly contribute to this development. 
Table 2. Different ways of financing

\begin{tabular}{cccccc}
\hline Sports Society & Sports Season & TA & IA & Members * & Funding Obtained * \\
\hline SAD A & $2008 / 2009$ & $1,129,712$ & 223,284 & & \\
SAD A & $2009 / 2010$ & $1,289,379$ & 128,424 & & \\
SAD A & $2010 / 2011$ & $1,313,399$ & 177,641 & & $2,072,959$ \\
SAD A & $2011 / 2012$ & $1,414,477$ & 445,692 & & $1,629,218$ \\
SAD A & $2012 / 2013$ & $1,358,207$ & 105,332 & & $1,434,651$ \\
SAD A & $2013 / 2014$ & $2,554,153$ & $1,055,000$ & $2,993,177$ & 207,730 \\
SAD A & $2014 / 2015$ & $3,004,253$ & 433,368 & $2,840,141$ & $1,475,447$ \\
SAD A & $2015 / 2016$ & $3,481,120$ & 184,585 & $2,840,141$ & 985,553 \\
SAD A & $2016 / 2017$ & $5,061,750$ & 395,375 & & 12,995 \\
SAD A & $2017 / 2018$ & $5,670,269$ & 246,590 & & $1,566,021$ \\
SAD B & $2008 / 2009$ & $1,564,523$ & 105,043 & & 1969 \\
SAD B & $2009 / 2010$ & $1,355,229$ & & & 11,091 \\
SAD B & $2010 / 2011$ & $1,197,249$ & 75,000 & & 212,612 \\
SAD B & $2011 / 2012$ & $1,689,548$ & 50,000 & & 330,218 \\
SAD B & $2012 / 2013$ & $1,259,178$ & & & 221,227 \\
SAD B & $2013 / 2014$ & 227,569 & 504,840 & & 343,088 \\
SAD B & $2014 / 2015$ & 440,973 & 413,189 & & $1,391,369$ \\
SAD B & $2015 / 2016$ & 647,605 & $2,130,604$ & & $3,596,528$ \\
SAD B & $2016 / 2017$ & 722,728 & $5,882,776$ & & $3,501,321$ \\
SAD B & $2017 / 2018$ & $1,244,610$ & $5,297,822$ &
\end{tabular}

Regarding economic and financial growth, it is certain that qualification brings with it direct impacts (participation bonuses) and indirect impacts (other sources of revenue). In the sample, the general liquidity indicator (Figures 1 and 2) revealed treasury difficulties in both clubs after participating in European competitions. In the case of SAD A, the indicator remained below 0.50 in the periods following participation, which suggests that qualification had no impact on the ability to settle short-term commitments. The same happened to SAD B, although in this case, the indicator was constant and always higher than 0.50 . We believe that the increase in investment has directly influenced the indicator. Despite this, there are strong indications that qualification did contribute to the economic and financial growth of both clubs.

\section{Sport Society A}

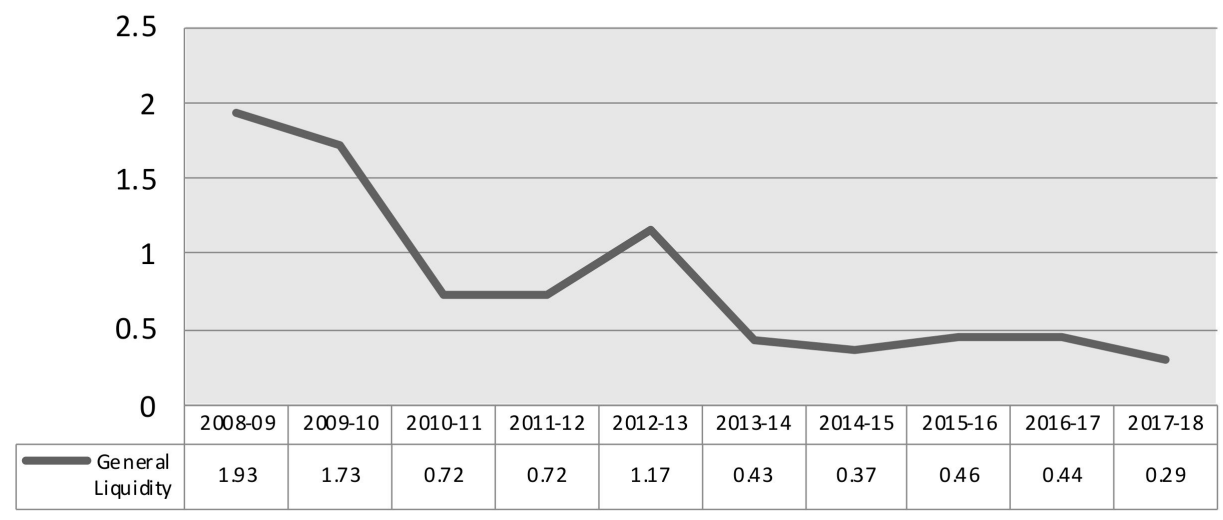

Figure 1. General liquidity for SAD A. 


\section{Sport Society B}

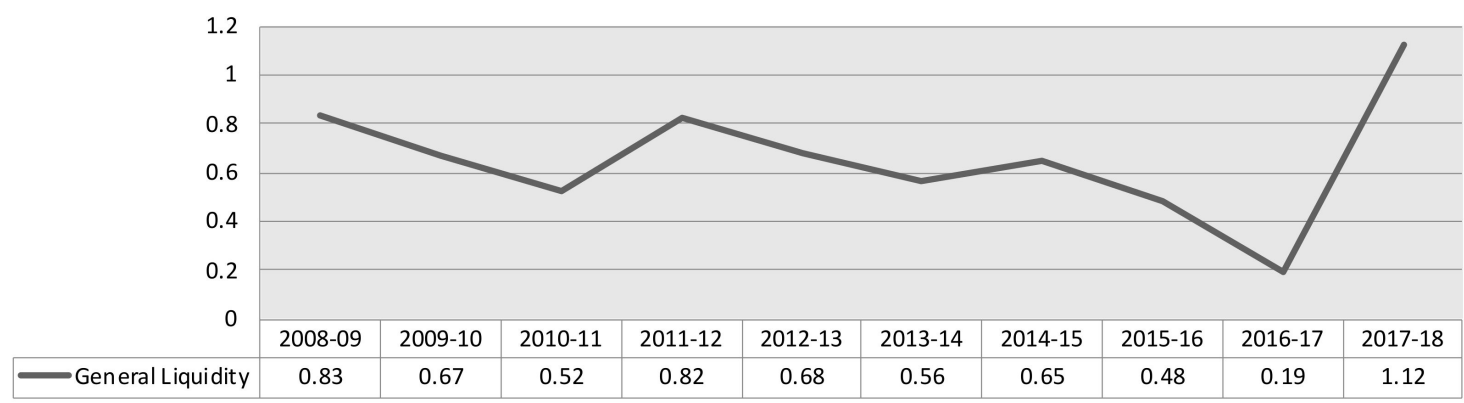

Figure 2. General liquidity for SAD B.

In terms of indebtedness (Figures 3 and 4), the evidence suggests that the direct impacts (participation premiums) are not sufficient for clubs to finance their activity in the short term. Indirect impacts (other sources of revenue), on the other hand, make it possible to achieve a financial balance in the medium and long term; however, these are not immediate. Everything indicates that after qualification, there is a tendency to intensify short-term investments; however, contrary to expectations, direct returns are not always sufficient to finance them, and the indirect impacts appear to not be immediate. This situation inevitably leads to excessive indebtedness, with the expectation of future returns. The results showed that in the case of SAD A, the expected return with indirect impacts did not happen and led the club to a situation of apparent technical bankruptcy. This situation leads us to believe that the fact that the impacts (direct and indirect) occur at different times, conditions the short-term financial balance, and the expectation of future returns influence the degree of indebtedness considerably. Therefore, this indicator reveals that quantitative economic and financial growth is not always positively affected by qualification.

\section{Sport Society A}

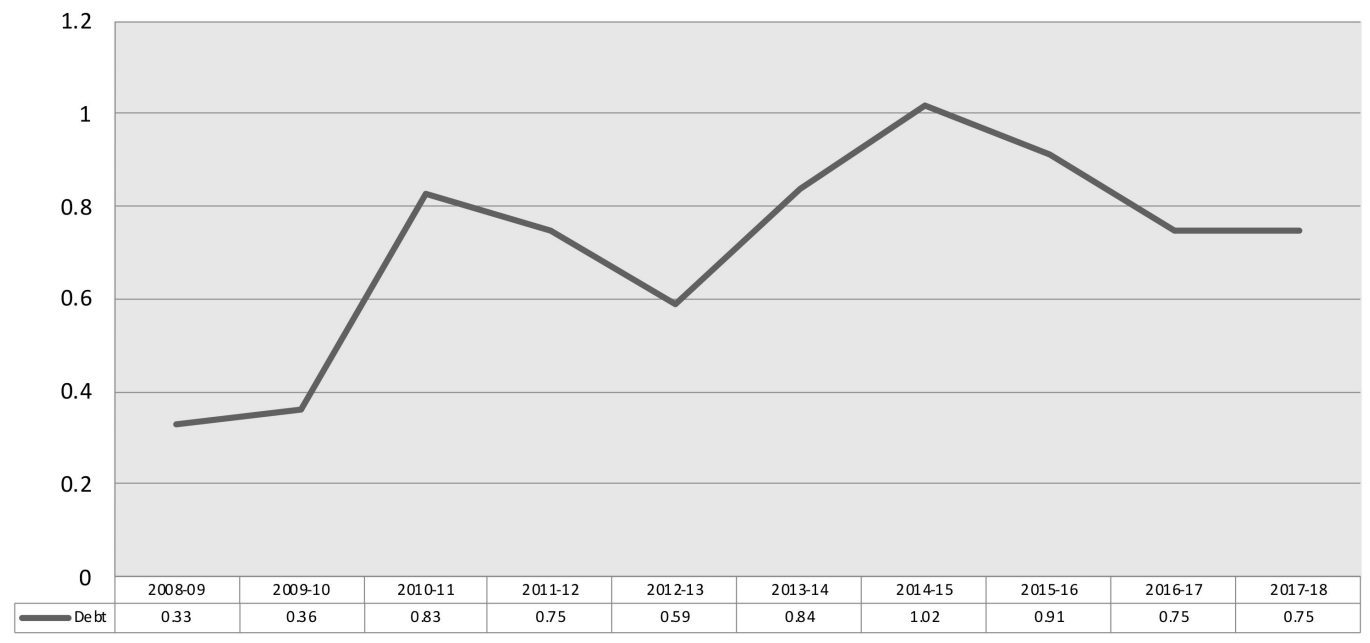

Figure 3. Debt for SAD A. 


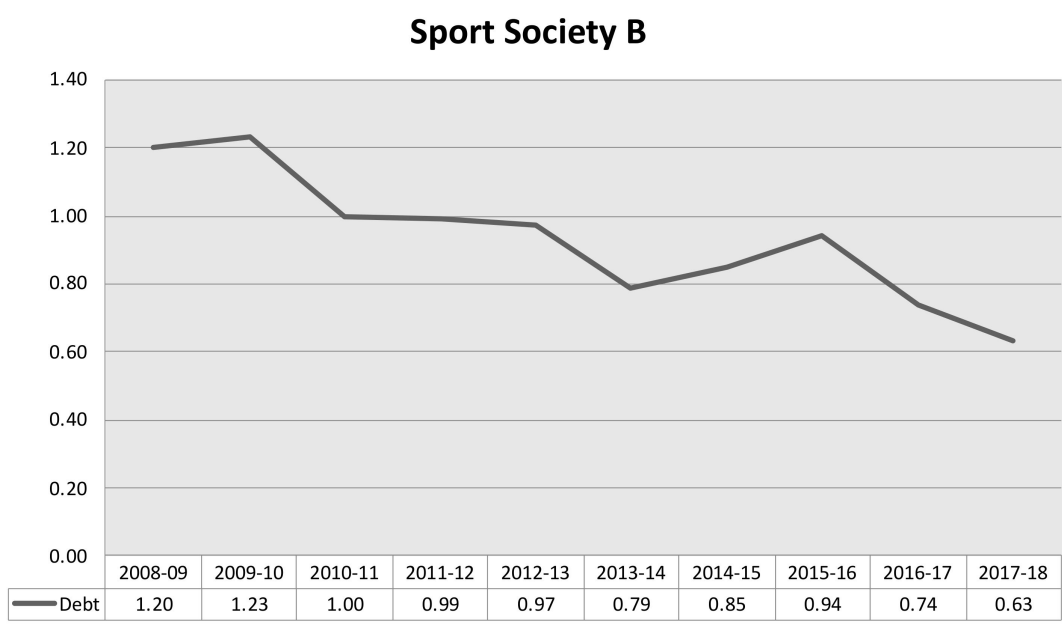

Figure 4. Debt for SAD B.

Finally, the analysis of the solvency indicator (Figures 5 and 6) shows that in the short term, qualification does not immediately improve the ability to resolve commitments in the medium and long terms via equity, and may even take several sports seasons. However, the results presented also reveal that frequent qualification leads to a rapid improvement in the indicator. In the case of SAD $\mathrm{B}$, the second qualification shows a significant improvement in the indicator in the season following participation in the UEFA Europa League. We believe that the recurring qualification, in itself, can have a significant impact on indirect returns, which will allow positive net results. Thus, if investments are prudent in the three phases of qualification (qualification, participation, and post-participation) and indirect returns happen, this can positively affect quantitative economic-financial growth.

\section{Sport Society A}

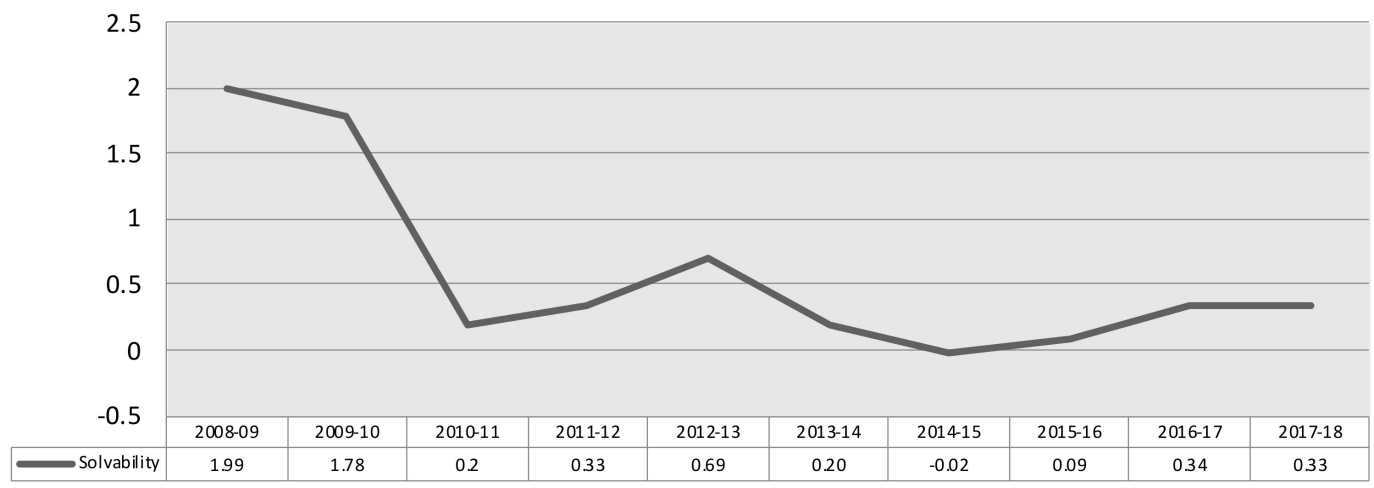

Figure 5. Solvability of SAD A.

Regarding the sources of revenue (Table 3) most affected by qualification (variables included in the income account item), it seems reasonable to say that the rights of athletes (gains in the transaction and assignment) have a more significant impact. Second is television rights (selling rights to games at home). The results also revealed that in the case of SAD A, qualification for UCL did not have an impact on ticket sales, cabins, and captives. On the contrary, SAD B saw an increase in ticket sales, cabins, and captives, especially for the second qualification and subsequent seasons. An interesting fact is that the results present a minor impact on commercial activity (sponsorship, advertising, and corporate) in the sample. We believe that good sporting performance in the national championship, which leads to qualifying for European competitions, appears to be the main driver of the impact on the main sources of revenue. The fact that they are small clubs that belong to a minority and have reach such a desired place arouses greater interest from investors. However, for the adept mass, 
qualification is not a sufficient condition to boost consumption, which may justify the insignificant impacts on merchandising or ticket revenues (Table 3).

\section{Sport Society B}

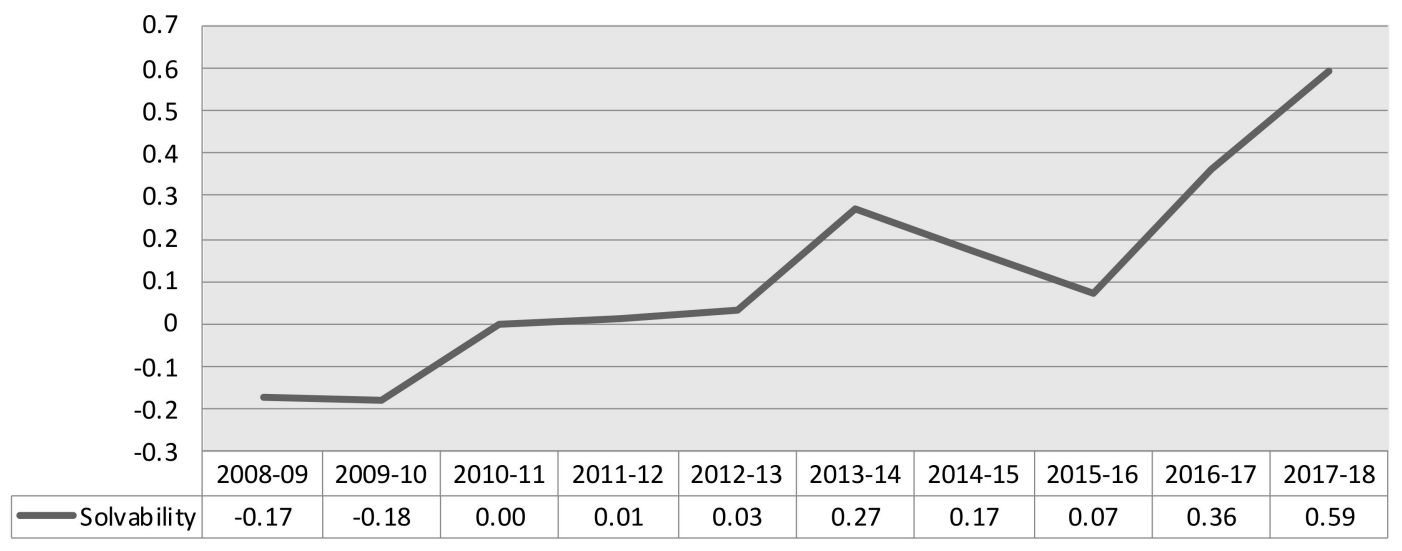

Figure 6. Solvability of SAD B.

Table 3. Profits (sources of revenue).

\begin{tabular}{ccccccc}
\hline $\begin{array}{c}\text { Sport } \\
\text { Society }\end{array}$ & $\begin{array}{c}\text { Sport } \\
\text { Season }\end{array}$ & $\begin{array}{c}\text { Athletes } \\
\text { Rights * }\end{array}$ & $\begin{array}{c}\text { Television } \\
\text { Rights * }\end{array}$ & Competitions * & $\begin{array}{c}\text { Commercial } \\
\text { Activity * }\end{array}$ & $\begin{array}{c}\text { Income from } \\
\text { the Ticketing * }\end{array}$ \\
\hline SAD A & $2008 / 2009$ & N/A & N/A & N/A & 76,448 & N/A \\
SAD A & $2009 / 2010$ & N/A & N/A & N/A & 41,800 & N/A \\
SAD A & $2010 / 2011$ & 108,530 & $2,120,000$ & 3395 & 27,838 & 326,232 \\
SAD A & $2011 / 2012$ & $1,003,780$ & $1,836,000$ & 2143 & 2009 & 116,989 \\
SAD A & $2012 / 2013$ & $3,278,100$ & $1,800,000$ & & 1083 & 94,399 \\
SAD A & $2013 / 2014$ & $1,465,000$ & $2,040,000$ & $4,003,361$ & 1305 & 172,361 \\
SAD A & $2014 / 2015$ & 748,494 & $2,000,000$ & 603,003 & 5176 & 124,635 \\
SAD A & $2015 / 2016$ & $2,047,982$ & $2,500,000$ & 37,293 & 3296 & 111,659 \\
SAD A & $2016 / 2017$ & $6,518,900$ & $3,026,277$ & 44,462 & 4209 & 187,551 \\
SAD A & $2017 / 2018$ & $1,858,744$ & $3,000,000$ & 60,795 & 7655 & 250,975 \\
\hline SADB & $2008 / 2009$ & & $1,709,642$ & & 750 & 233,230 \\
SAD B & $2009 / 2010$ & & $1,673,213$ & & 14,540 & 327,271 \\
SAD B & $2010 / 2011$ & & $1,800,000$ & & 20,064 & 204,838 \\
SAD B & $2011 / 2012$ & $2,650,000$ & $1,800,000$ & & 13,555 & 155,805 \\
SAD B & $2012 / 2013$ & N/A & N/A & N/A & N/A & N/A \\
SAD B & $2013 / 2014$ & $1,319,422$ & $2,040,000$ & & 2,439 & 183,960 \\
SAD B & $2014 / 2015$ & $1,161,000$ & $2,050,000$ & $2,290,088$ & 55,000 & 232,789 \\
SAD B & $2015 / 2016$ & $1,736,000$ & $3,280,990$ & 733,945 & 53,368 & 404,423 \\
SAD B & $2016 / 2017$ & $20,990,675$ & $3,230,000$ & 235,000 & 44,600 & 367,305 \\
SAD B & $2017 / 2018$ & $3,070,651$ & $2,200,000$ & 26,280 & 114,175 & \\
\hline
\end{tabular}

* All values in euros.

As for the timing of the economic and financial impacts, there is evidence to associate the impact of the type of revenue source. In the case of player transactions, which is one of the main sources of revenue, the results seem to be consensual and indicate a significant increase in the second and third sports season after participation. An interesting fact, although subject to a more in-depth investigation, is that when the period that separates the participations is only a sporting season, this income tends to be immediate even when qualifying. Regarding the second source of revenue, television rights, the results revealed different moments of impact. In the case of SAD A, performance increased, but only three sporting seasons after qualifying. We understand that the financial difficulties that the club went through after participating in the UEFA Champions League did not allow for negotiation of television rights, and could be the cause of an atypical impact. Concerning SAD B, the impact on the source of 
revenue occurred in the two periods following participation in the UEL. Therefore, the study allowed us to verify that the impacts of qualification are not immediate, and are dependent on several factors.

Finally, statistical analysis applied to the indicators considered most relevant (Table 4) revealed statistically significant differences, at a $5 \%$ level, on the distribution of the general liquidity for SAD A before and after qualification, i.e., before 2013/2014 and after that period. For SAD B, significant differences were registered for the distribution of the indicators debt and solvability before and after qualification, i.e., before 2014/2015 and after that period.

However, this change, which precedes a sporting season marked by cash flow difficulties, already identified in the liquidity indicator, is related to the increase in current liabilities via loans obtained some time after the first internationalization.

Results from the Wilcoxon rank test for the financial indicators are presented in Table 4. Although the indicators may be closely correlated, the univariate aspect of the test overcomes multicollinearity problems. Based on the results of the statistical analysis, it is possible to verify that for SAD A, the general liquidity indicator showed statistically significant differences $(p<0.05)$. These data reveal that there was a statistically significant effect of qualification for European competitions on the financial sustainability of the club; however, this effect was not positive. In the previously presented results, it was verified that the club had treasury difficulties before qualifying; however, management invested in its assets in the expectation of immediate returns, which did not happen, aggravating the lack of liquidity and inevitably leading to an apparent technical bankruptcy after qualification.

Table 4. Wilcoxon rank test results for economic and financial indicators comparison before and after qualification (internationalization) for the two sports societies A and B.

\begin{tabular}{ccccc}
\hline & \multicolumn{2}{c}{ SAD A } & \multicolumn{2}{c}{ SAD B } \\
Indicator & W Statistic & $\boldsymbol{p}$-Value & W Statistic & $\boldsymbol{p}$-Value \\
\hline Debt & 3 & 0.057 & $22 *$ & 0.038 \\
General Liquidity & $25 *$ & 0.012 & 16 & 0.476 \\
Solvability & 21 & 0.093 & $2 *$ & 0.038 \\
\hline * Significant differences before and after qualification, at a level of $5 \%$.
\end{tabular}

Regarding SAD B, based on the results of the statistical analysis, it is possible to verify the existence of two indicators with statistically significant results $(p<0.05)$. These indicators were debt and solvency. These indicators related the ability to finance via equity with a reduction in the demand for foreign capital. The statistical analysis once again reveals a statistically significant effect of qualifying for European competitions on the club's financial sustainability. However, this effect is not positive, maybe because qualification implies investment, and the financial capacity is reduced for small clubs, and the fact that the returns are not immediate also aggravates the situation and slows down financial recovery.

In short, liquidity difficulties should serve as an important warning signal for small clubs that qualify for European competitions, and the investments to be made using foreign capital must be well evaluated. Qualification is a cycle that we can say has its beginnings in qualifying, which is the moment when the financial situation of the club must be evaluated such that in the instant following the cycle of participation in international competitions, there is financial balance. The cycle ends after qualification, and small clubs must be financially sustainable.

The indicators applied in this study, in addition to being the most suitable for analysis of the financial sustainability of any organization [9], presented themselves as the most relevant in the financial analysis of sports societies, particularly in the football industry. Through these indicators, the applied methodology allowed for the identification of significant effects, positive or negative, which is fundamental for management bodies to define the strategies to be adopted. 


\section{Discussion and Conclusions}

With Table 1, it is intended to show the attitude of each club regarding the priority in terms of investments in two of the main structural dimensions (infrastructure and squad). The excessive investment in tangible assets (infrastructure) to the detriment of intangible assets (players) may eventually result in a poor performance in European competitions, and even lead to demotion in national competition. This fact shows that it is not only the excessive investment in players that can lead a club to poor sporting performance in European competitions [5] but also the insufficient investment in players can interfere with sports results. There must be a balance that is not detrimental to the club's sporting performance. On the other hand, the overlapping illusion of belonging to the elite in terms of high investment in players can result in financial difficulties $[1,2,6,13]$.

The existence of a relation between qualification and the increase in indebtedness can ultimately lead to technical failure. This reality demonstrates that the benefits of qualification do not always outweigh the investments made [7]. Participation bonuses (direct impacts) are not always the main source of investment financing, which can justify excessive indebtedness during the qualification phases. It appears that for the clubs under analysis, large financial investments preceded direct revenues (participation and ticket prices); however they were only made because the qualification for the competitions was verified. This position contradicts, at least in small clubs, the theory that clubs invest in the long term to achieve qualification [6]. The use of private financing by clubs based on sporting and financial expectations, as a management strategy, leads to financial instability during qualification $[1,2,5]$. This situation leads, in the short term, to financing difficulties, thus contradicting one of UEFA's main objectives with the expansion of competitions (financial balance and equity) [1].

It is worth highlighting the different moments in which the economic and financial impacts were verified in clubs, which can condition the financial balance in the short term, and force the increase of the indebtedness to face the investments $[1,6]$. It appears that the expectation with the valuation of intangible assets after qualification can also contribute to the high indebtedness. On the contrary, the existence of an appreciation of these assets, for example, contributes to a greater capacity for negotiating loans and their maturity. These results reveal the importance of a clear definition of goals by the clubs, and an awareness of their limitations [8]. For small clubs, the strong dependence on player transactions (indirect impacts) reveals the structural fragility of these clubs. In addition, it partially contradicts the perspective defended by [1] regarding the importance of indirect revenues for clubs with lower incomes. The inability to generate revenues capable of exceeding the investments made with income from player transactions is very clear [7]. Qualification in itself is already significant in indirect returns, so the containment of investments in tangible assets must be considered [1]. The fleeting nature of impacts [7] must be seen as a reality when defining objectives and making decisions [8]. Managers have the role of defining clear strategies that have the ultimate goal of financial balance [15]. Investors' interest in revelation teams quickly dissipates [2], which shows some instability in these impacts.

Despite the positive evidence of the effects of qualification, the impact on economic and financial indicators is not always significant. The problem may be related to the stage of the competition reached by the clubs [7].

Qualification is a window of opportunity that must, however, be viewed with caution. The maintenance or improvement of financial sustainability of small clubs must be very present on the horizon of managers, and cannot be put in the background [10]. In this sense, the ability to make the best decisions at the right time is essential in this process. This article shows evidence that qualification affects the development of small clubs, and that access to millionaire leagues, albeit discreetly, allows for very interesting financial inputs. The raised funds favor investment in improving assets and contribute to the development and quantitative growth of clubs, though in different ways. We also found that the demand for improving sports performance in the short term can lead to excessive investment and consequent indebtedness, which would jeopardize good financial performance. Thus, prudence in investments must be the main basis when facing qualification. 
This attitude demonstrates the ability to manage the success of the moment with an awareness of the volatility and uncertainty that characterize the football industry. Therefore, good management is essential to balance the different interests of clubs. The obtained results also reveal that the economic and financial impacts on small clubs is not immediate, and that it essentially affects the revenue directly related to player transactions. It has been shown that the impact on the remaining sources of revenue is not significant (except for television rights), nor is it beneficial if managed inefficiently. Despite UEFA's efforts to monitor the financial performance of clubs participating in European competitions, there are still parallel realities that are not well controlled. Recent studies point to progressive improvements in financial stability and sustainability in the main European clubs after the introduction of FFP [19]. However, the reality for small clubs still seems to be far away from that goal. The presented results are not sufficient to show that the way the qualification process took place in the sample has the same implications for all small clubs. However, they reflect two realities and can serve as a guide for other clubs. Nonetheless, future studies of other small clubs may show whether there is a pattern of behavior in these clubs.

Author Contributions: F.D. and R.S. had the initial idea for the manuscript and wrote an original draft as well as providing the resources for the research, and A.B. participated in the formal reviews and supervision of the statistical analysis. All authors have read and agreed to the published version of the manuscript.

Funding: The work of the author Ana Borges is supported by national funds through FCT—Fundação para a Ciência e Tecnologia through project UIDB/04728/2020. The work of the author R.S. is supported by national funds, through the FCT-Portuguese Foundation for Science and Technology under the project UIDB/04011/2020.

Conflicts of Interest: The authors declare no conflict of interest.

\section{References}

1. Dima, T. The Business Model of European Football Club Competitions. Procedia Econ. Financ. 2015, 23, 1245-1252. [CrossRef]

2. Rohde, M.; Breuer, C. Europe's Elite Football: Financial Growth, Sporting Success, Transfer Investment, and Private Majority Investors. Int. J. Financ. Stud. 2016, 4, 12. [CrossRef]

3. Dimitropoulos, P.E.; Koronios, K. Earnings Persistence of European Football Clubs under UEFA's FFP. Int. J. Financ. Stud. 2018, 6, 43. [CrossRef]

4. Bullough, S. UEFA champions league revenues, performance, and participation 2003-2004 to $2016-2017$. Manag. Sport Leis. 2018, 23, 139-156. [CrossRef]

5. Andreff, W. Financial and Sporting Performance in French Football Ligue 1: Influence on the Players' Market. Int. J. Financ. Stud. 2018, 6, 91. [CrossRef]

6. Franck, E. European Club Football after "Five Treatments" with Financial Fair Play-Time for an Assessment. Int. J. Financ. Stud. 2018, 6, 97. [CrossRef]

7. Cox, A.; Gilmore, S.; Graham, A. The European dilemma: Evaluating the implications of UEFA Europa League participation on English Premier League clubs. Soccer Soc. 2017, 18, 817-835. [CrossRef]

8. Plumley, D.; Flint, S.W. The UEFA Champions League: Maintaining the status quo? Team Perform. Manag. 2015, 21, 247-258. [CrossRef]

9. Pulatovich, E.M. Impact of financial sustainability on enterprise value expansion. Int. J. Eng. Adv. Technol. 2019, 9, 4640-4645. [CrossRef]

10. Mesa Callejas, R.J.; Osorio Agudelo, J.A.; Castaño Rios, C.E. Economía, Gestión y Fútbol: De la Pasión a la Sostenibilidad Financiera [Economics, Management and Football: Passion to Financial Sustainability]; MPRA Paper 72778; University Library of Munich: Munich, Germany, 2016.

11. Barajas, A.; Castro-Limeres, O.; Gasparetto, T. Application of MCDA to evaluate financial fair play and financial stability in european football clubs. J. Sports Econ. Manag. 2017, 7, 143-164.

12. D'Andrea, A.; Masciandaro, D. Financial Fair Play in European Football: Economics and Political Economy-A Review Essay; BAFFI CAREFIN Centre Research Paper No. 2016-15; Bocconi University: Milan, Italy, 2016.

13. Lago, U.; Simmons, R.; Szymanski, S. The financial crisis in European football: An introduction. J. Sports Econ. 2006, 7, 3-12. [CrossRef] 
14. Beech, J.G.; Beech, J.; Chadwick, S. (Eds.) The Business of Sport Management; Pearson Education: London, UK, 2004.

15. Zineb, J.; Said, O. Sport and Financial Performance Analysis $f_{c}$ Barcelona Club Case L'analyse de la Performan ce Sportive et Financière; Cas du Club fc Barcelone: London, UK, 2016; p. 105.

16. Lin, M.Y. Deposit insurance and effectiveness of monetary policy. Appl. Econ. Lett. 2015, 22, 1443-1449. [CrossRef]

17. Windberger, T.; Zeileis, A. Structural breaks in inflation dynamics within the European Monetary Union. East. Eur. Econ. 2014, 52, 66-88. [CrossRef]

18. Zeileis, A.; Shah, A.; Patnaik, I. Testing, monitoring, and dating structural changes in exchange rate regimes. Comput. Stat. Data Anal. 2010, 54, 1696-1706. [CrossRef]

19. Caglio, A.; D'Andrea, A.; Masciandaro, D.; Ottaviano, G.I. Does Fair Play Matter? UEFA Regulation and Financial Sustainability in the European Football Industry. UEFA Regulation and Financial Sustainability in the European Football Industry (1 October 2016); BAFFI CAREFIN Centre Research Paper No. 2016-38; Bocconi University: Milan, Italy, 2016.

Publisher's Note: MDPI stays neutral with regard to jurisdictional claims in published maps and institutional affiliations.

(C) 2020 by the authors. Licensee MDPI, Basel, Switzerland. This article is an open access article distributed under the terms and conditions of the Creative Commons Attribution (CC BY) license (http://creativecommons.org/licenses/by/4.0/). 